\title{
EL NUEVO PARADIGMA DE DESARROLLO RURAL. REFLEXIÓN TEÓRICA Y RECONCEPTUALIZACIÓN A PARTIR DE LA RURAL WEB ${ }^{1}$
}

\author{
Eloi Guinjoan \\ Anna Badia \\ Antoni F. Tulla \\ Departament de Geografia. Universitat Autònoma de Barcelona \\ eloi.guinjoan@uab.cat, anna.badia@uab.cat, antoni.tulla@uab.cat
}

\section{RESUMEN}

En este artículo, se presenta una revisión sintetizada de la literatura más relevante acerca del nuevo paradigma de desarrollo rural. A partir de ello, se argumenta que los diversos cuerpos teóricos involucrados en su teorización aún están demasiado desconectados. En este sentido, se subraya la necesidad de nuevas conceptualizaciones como el modelo de la rural web (van der Ploeg y Marsden, 2008), un marco teórico integrado que concibe el desarrollo rural como la continua revitalización de la compleja red de personas, recursos, actividades y procesos que interactúan en un territorio y modelan su atractivo social, económico, cultural y ambiental.

Palabras clave: desarrollo rural, multifuncionalidad, sistema agroalimentario, capital social, rural web.

\section{ABSTRACT}

The New Paradigm of Rural Development. Theoretical Considerations and Reconceptualization Using the 'Rural Web'. In this paper, we provide a synthesized review of the most

Fecha de recepción: julio 2014.

Fecha de aceptación: marzo 2015.

1 Este artículo se inscribe en el marco del proyecto de investigación Desarrollo rural en áreas de montaña: la segunda mejor opción en el territorio como instrumento para la diversificación productiva (CSO2012-31979), financiado por el Ministerio de Economía y Competitividad, y cuyo investigador principal es el Dr. Antoni F. Tulla. La elaboración del artículo ha sido posible gracias a una beca del Programa de Formación del Profesorado Universitario (FPU), del Ministerio de Educación, Cultura y Deporte. 
relevant literature about the new paradigm of rural development. On this basis, it is argued that the different theoretical bodies that comprise this literature are still too disconnected. In this regard, we highlight the need for new conceptualizations such as the 'rural web' model (van der Ploeg and Marsden, 2008), an integrated theoretical framework which conceives rural development as the ongoing revitalization of the complex network of people, resources, activities and processes that interact in an area and shape its social, economic, cultural and environmental attractiveness.

Keywords: rural development, multifunctionality, agri-food system, social capital, rural web.

\section{INTRODUCCIÓN}

Durante las últimas décadas del siglo XX, se ha producido un importante giro en la forma de plantear el desarrollo rural en Europa. En efecto, se ha abandonado el tradicional enfoque exógeno y sectorial, propio del paradigma de la modernización, y se ha apostado por un nuevo enfoque de carácter más local, endógeno e integrado, donde los objetivos económicos son combinados con otros de carácter social y ambiental (Woods, 2011).

La teorización de este nuevo enfoque de desarrollo rural ha vivido un importante avance durante los últimos 15 años, con aportaciones desde disciplinas y ópticas muy diversas. A raíz de un estudio anterior (Guinjoan et al., 2014), los autores ya comprobamos la necesidad de adentrarnos en conceptualizaciones del desarrollo rural más elaboradas y adaptadas al contexto actual. En este artículo, nuestro objetivo es efectuar una reflexión teórica acerca de este nuevo paradigma de desarrollo rural, con la intención de aportar un poco de luz sobre el eterno debate alrededor del significado y las implicaciones del desarrollo rural.

Para ello, nuestra metodología se ha basado en revisar y sintetizar toda la literatura más relevante que ha aparecido sobre estos nuevos planteamientos de desarrollo rural, con la finalidad de identificar los múltiples cuerpos teóricos involucrados en su conceptualización y ofrecer una visión de conjunto del fenómeno. Adicionalmente, para completar nuestra reflexión teórica también efectuaremos una mirada crítica sobre la literatura revisada. Por un lado, defenderemos la conveniencia de abandonar las múltiples variaciones terminológicas que existen para hacer referencia al nuevo enfoque de desarrollo rural y de concretar un único término, simple y flexible, que facilite su definición y evite confusiones innecesarias. Por otro lado, también se argumentará que los diferentes cuerpos teóricos que integran dicha literatura están demasiado desconectados entre sí, lo que dificulta claramente la obtención de una visión de conjunto acerca de este nuevo paradigma de desarrollo rural.

Consecuentemente, se destacará la necesidad de desarrollar y consolidar nuevos marcos teóricos integrados como el modelo de la rural web (van der Ploeg y Marsden, 2008), que presentaremos y valoraremos de forma exhaustiva, poniendo énfasis en la reconceptualización que supone del desarrollo rural y en su potencial para ser utilizado como herramienta de análisis y diagnosis.

Finalmente, construiremos una definición de desarrollo rural, poniendo énfasis en la necesidad de complementar la exhaustiva literatura existente con nuevas definiciones que nos ayuden a precisar qué es exactamente el desarrollo rural como objetivo y, en consecuencia, qué es lo que persigue este nuevo paradigma analizado desde la literatura. 


\section{ANTECEDENTES Y GÉNESIS DEL NUEVO PARADIGMA DE DESARROLLO RURAL}

\section{II.1. Un repaso al anterior paradigma de la modernización}

Pese a una generalizada visión del mundo rural como realidad estable y romántica, la verdad es que las áreas rurales siempre han sido dinámicas y se han visto constantemente sometidas a múltiples fuerzas de cambio (Hoggart y Paniagua, 2001). Sin embargo, con la finalización de la Segunda Guerra Mundial, las transformaciones de las áreas rurales se vieron profundamente acentuadas, ya que estos territorios empezaron a sufrir los efectos de la consolidación del modelo urbano e industrial, basado en un sistema de producción fordista, que convertía la concentración de factores en la receta ideal para el crecimiento económico. Como consecuencia, tuvo lugar una redistribución de población, recursos e inversiones que se tradujo en una nueva estructuración del territorio en centros y periferias, tanto a escala regional como global (Oliva Serrano, 1997: 327).

En este contexto, el enfoque tradicional adoptado para el desarrollo descansaba en la idea de la modernización, según la cual todas las sociedades evolucionan de forma lineal desde un estado irracional y tecnológicamente limitado, hasta un estado racional y tecnológicamente avanzado, significando esta transición el paso de una sociedad tradicional hacia una sociedad moderna (Taylor, 1989: 305). Este afán modernizador situó la consecución de una economía nacional fuerte como objetivo primordial, por lo que las escalas local y regional cedieron todo el protagonismo a la escala estatal. Los centros urbanos eran vistos como polos de crecimiento, mientras que las áreas rurales se consideraban territorios atrasados y con una función meramente productiva, aunque con criterios de rentabilidad. Así, el desarrollo rural se enfocó desde un planteamiento exógeno, por el cual había que traer la modernidad desde la ciudad hacia el campo y, más concretamente, al sector agrícola (Ward et al., 2005: 4).

La emergencia de la agricultura productivista, caracterizada por la mecanización e industrialización de los procesos agrarios, generó tres nuevas dinámicas: la intensificación de la producción, la concentración de las unidades productivas y la especialización de la producción. Estas dinámicas, a su vez, tuvieron múltiples efectos: algunos de carácter ambiental, como la pérdida de hábitats y de biodiversidad, el deterioro de los suelos o el incremento de la contaminación (Green, 1981); otros de carácter económico y social, como el despoblamiento del campo, la dependencia de otros sectores económicos, la pérdida de peso de la agricultura y la emergencia de una nueva ruralidad polivalente, caracterizada por una gran diversidad de actividades (García Ramon et al., 1995). Así, el productivismo agrario se ha manifestado como un proceso ciertamente contradictorio, ya que pese a apostar por la especialización agrícola de las áreas rurales, acabó provocando el declive de la agricultura en el mundo occidental, un hecho al que Woods (2011: 78) se refiere como «la paradoja del productivismo».

En definitiva, el paradigma de la modernización, basado en un enfoque exógeno y sectorial para el desarrollo rural, condenó a las áreas rurales a una función meramente productiva entre 1945 y la década de los ochenta (Furmankiewicz, 2012: 262). Así, el desarrollo rural de la postguerra se centró únicamente en el crecimiento económico, dejando de lado cualquier consideración de carácter ambiental, social y cultural, un hecho que nos invita a reflexionar sobre si la modernización rural realmente trajo desarrollo (Markantoni et al., 2013). 
En este sentido, hay que tener presente que el concepto de desarrollo es una construcción social que depende inevitablemente del contexto espacial y temporal. Por este motivo, podemos entender que en su momento, el simple crecimiento económico ya fuera concebido como desarrollo para las áreas rurales (Pike et al., 2007). No obstante, desde la perspectiva actual, el concepto incluye toda una serie de connotaciones de carácter social, ecológico, político y cultural que no permiten entender un simple incremento cuantitativo como desarrollo, sino que además también se pide una mejora cualitativa, confiriendo así importancia a nuevos aspectos como el equilibrio territorial, la calidad de vida, la capacidad creativa, etc. (Ojeda Rivera, 2004: 276).

\section{II.2. Origen y filosofía del nuevo paradigma}

A partir de la década de los sesenta, se empezó a cuestionar la preponderancia de los criterios económicos en el funcionamiento de la sociedad, un hecho que provocó la aparición de las primeras voces críticas con el paradigma de la modernización y sus políticas de desarrollo exógeno, exclusivamente centradas en aspectos económicos (Pike et al., 2007: 1254). En este sentido, hay que mencionar al economista Celso Furtado, que ya en 1961 plantea una reinterpretación del desarrollo, defendiendo la necesidad que éste incluya modificaciones estructurales y valores sociales y apostando así por un enfoque endógeno (Furtado, 1961).

En este contexto, alrededor de 1965 surgen ya las primeras estrategias de desarrollo impulsadas desde el ámbito local en algunas áreas rurales francesas, con la intención de combatir la caída de actividad dentro de un estado profundamente centralizado e intervencionista (Dalla Rosa, 1999: 33). Pocos años después, la crisis económica de la década de los setenta puso de manifiesto que las políticas regionales de carácter centralista y afán modernizador eran incapaces de generar desarrollo en las regiones periféricas, donde la economía seguía dependiendo de decisiones externas (Cappellin, 1992: 2). Así, en un contexto de reestructuración económica mundial y elevadas disparidades regionales, las comunidades locales se empezaron a organizar para hacer frente a los nuevos retos internacionales a partir de iniciativas propias (Stöhr, 1992: 204).

En consecuencia, a partir de la década de los años setenta, la idea del desarrollo se empieza a abordar desde una perspectiva más local y centrada en las personas. Poco a poco, aquel concepto que antes se asociaba con crecimiento económico, fue adquiriendo una dimensión cualitativa que se preocupaba por el carácter, la calidad y la sostenibilidad del crecimiento (Pike et al., 2007). El enfoque exógeno y sectorial fue criticado por promover un desarrollo dependiente, desigual, homogeneizador e impuesto (Ward et al., 2005: 4) y, en contraposición, la política regional europea fue sustituyendo los enfoques tradicionales topdown por nuevos enfoques bottom-up, es decir, planteados desde abajo.

Se abandonaron así las anteriores posiciones paternalistas que querían traer el desarrollo a las áreas desfavorecidas desde fuera y se puso énfasis en fomentar el emprendimiento y las iniciativas locales (Pujadas, 2003: 49). Consecuentemente, podemos considerar que el marco histórico, social, político y económico del enfoque contemporáneo de desarrollo rural deriva indirectamente de la compleja transición que experimentaron las áreas rurales europeas después de la Segunda Guerra Mundial, ya que se trata de un enfoque surgido como reacción al anterior paradigma de la modernización (van der Ploeg et al., 2008: 4). 
Las principales cuestiones que generaron controversia en torno a la modernización rural y las políticas agrarias productivistas fueron la sobreproducción, la degradación del medio ambiente y las desigualdades territoriales (Woods, 2011: 139). Adicionalmente, la instauración de cuotas lecheras, la caída del precio del trigo y el auge de una nueva consciencia ambiental durante la década de los años ochenta, confirmaron que el paradigma de la modernización rural estaba agotado y poco a poco se fue gestando una nueva forma de afrontar el desarrollo rural que se consolidó finalmente a partir de la década de los años noventa (van der Ploeg et al., 2000).

En este punto, conviene destacar que la reforma de la PAC de 1992, así como la creación e implementación de la iniciativa LEADER, tuvieron un papel destacado en la consolidación de esta nueva forma de pensar y afrontar el desarrollo de las áreas rurales, en la que se abandonaron los enfoques sectoriales y se apostó por nuevos planteamientos transversales que permitieran avanzar hacia el objetivo marcado de la cohesión territorial (Barke y Newton, 1997; Ray, 2001).

Las tres características principales de este nuevo enfoque son el uso de los recursos disponibles en el propio territorio, el control local sobre el proceso de desarrollo y la retención de beneficios en el ámbito local. Estos atributos lo llevaron a ser identificado como desarrollo endógeno, en contraposición al anterior modelo exógeno que había regido el paradigma de la modernización (Bowler, 1999). Sin embargo, con el tiempo se ha producido un creciente reconocimiento de la importancia que también tienen los factores extra-locales en el desarrollo rural (Lowe et al., 1995; Ray, 2001; Marsden y Smith, 2005). Esta constatación llevó a Ray (2001) a proponer el concepto de desarrollo neo-endógeno, precisamente con el objetivo de reconocer el papel que juegan los factores externos, pero la verdad es que muchos autores que venían utilizando el término original de desarrollo endógeno ya concebían la endogeneidad como un término flexible que podía incluir también factores extra-locales (Long y van der Ploeg, 1994; Bowler, 1999).

Por otro lado, varios autores han subrayado que los enfoques exógeno y endógeno tienen que ser entendidos como modelos ideales contrapuestos, pero en ningún caso como categorías excluyentes, ya que la escala local siempre interactúa con el ámbito extra-local (High y Nemes, 2007: 5; Galdeano-Gómez et al., 2011; Furmankiewicz, 2012: 265; Paül, 2013: 174). Así, pese a que algunos autores se empeñan en utilizar el concepto de desarrollo neoendógeno (Terluin, 2003; Shucksmith, 2010), mientras que otros se mantienen firmes en el uso de desarrollo endógeno (Vázquez Barquero, 2007; Vanclay, 2011), la mayoría de la literatura europea ya habla simplemente de desarrollo rural. En cualquier caso, lo relevante es que tanto unos como otros están haciendo referencia a un mismo enfoque para el desarrollo rural, de carácter relativamente endógeno, local e integrado.

La hipótesis que guía este nuevo enfoque es que cada territorio dispone de un conjunto de recursos económicos, sociales, tecnológicos, institucionales, infraestructurales, medioambientales y culturales que constituyen su potencial de desarrollo (Hernando, 2007: 7) y que puede ser traducido en bienestar socioeconómico si es gestionado desde una perspectiva territorial, bottom-up, colaborativa y respetuosa con el conocimiento y los valores locales (Furmankiewicz, 2012: 264). Así, el desarrollo rural deja de significar el seguimiento de una trayectoria predefinida, como sugería el anterior paradigma de la modernización, sino que tiene que ser entendido como un proceso gestado en el propio territorio y con posibilidad 
de ser construido en base a caminos muy diferentes (Ray, 1999), unas características que se verían claramente reflejadas en la implementación de la iniciativa comunitaria LEADER.

Este nuevo modelo de desarrollo ha comportado tres grandes cambios respecto el anterior enfoque exógeno: ha trasladado la atención sobre los recursos propios del territorio, ha convertido las comunidades locales en protagonistas del desarrollo y ha permitido un desarrollo integrado, gracias a la combinación de objetivos económicos, sociales y ambientales en un mismo territorio (Woods, 2011: 140). En cualquier caso, la ruptura que todo eso ha significado respecto al paradigma de la modernización, ha llevado a muchos autores a concebir este nuevo enfoque de desarrollo rural como un nuevo paradigma (van der Ploeg et al., 2000; Marsden y Sonnino, 2008; Kitchen y Marsden, 2009; Woods, 2011), es decir, como un nuevo marco o conjunto de ideas ampliamente reconocido bajo el cual se aborda el objetivo del desarrollo rural.

La consolidación de este nuevo paradigma durante las últimas décadas se ha visto materializada sobre las políticas rurales que vienen implementando los estados europeos. Así, podemos considerar que, por lo que se refiere a las políticas, el nuevo paradigma de desarrollo rural se ha traducido en una mayor preocupación hacia el patrimonio natural y cultural, en la sustitución de los subsidios a la agricultura por un soporte mucho más transversal a la áreas rurales y en un crecimiento de las políticas regionales basadas en recursos endógenos (Ward y Brown, 2009: 1239).

\section{LA TEORIZACIÓN DEL NUEVO PARADIGMA DE DESARROLLO RURAL}

Desde principios del siglo XXI, se han producido en Europa un gran número de actuaciones muy diversas en nombre del desarrollo rural. El análisis de sus impactos desde las ciencias sociales ha propiciado finalmente la aparición de nuevas conceptualizaciones que han permitido avanzar desde la práctica hacia la teoría. Algunos autores se han atrevido a apuntar cuáles son, a su entender, las dimensiones clave del desarrollo rural. En este sentido, la mayoría de clasificaciones separan los aspectos económicos o materiales, de los aspectos sociales e inmateriales (Knickel y Renting, 2000; Gralton y Vanclay, 2009). Adicionalmente, algunos autores han identificado una tercera dimensión clave, referente a los aspectos ambientales (Markantoni et al., 2013: 294). Sin embargo, otros autores han preferido englobar todas estas dimensiones en un solo concepto, el de capital territorial (Cebrián Abellán, 2003; van der Ploeg y Marsden, 2008).

Este artículo no quiere partir de ninguna clasificación predeterminada, sino ofrecer una visión completa y sintetizada de los múltiples cuerpos teóricos que han aportado luz sobre la teoría del nuevo paradigma de desarrollo rural. Así, pese a reconocer la utilidad de estas clasificaciones para tener siempre presente la multidimensionalidad del desarrollo rural, nosotros hemos optado por revisar toda la literatura más relevante y agruparla en grandes ámbitos temáticos, con la intención de ofrecer una visión integrada y a la vez esquematizada de todos los conceptos y cuerpos teóricos que nos tienen que ayudar a entender qué es realmente el desarrollo rural bajo el actual paradigma. Los tres grandes ámbitos temáticos resultantes, que veremos con detalle a continuación, hacen referencia al mundo rural como espacio de consumo, a la redefinición del sistema agroalimentario y a la revitalización de la esfera social. 


\section{III.1. La ruralidad como espacio de consumo}

La acumulación de grandes stocks de productos agroalimentarios, la controversia generada por el continuo dispendio público en agricultura y la aparición de una nueva conciencia ambiental, son las principales causas por las que, a partir de los años ochenta, se empezaron a dar una serie de cambios en las prácticas agrarias (Woods, 2011: 79). Estos cambios, propiciados en gran medida por las políticas agrarias europeas, pretendían enterrar el productivismo agrario e iniciar un nuevo período postproductivista caracterizado por la diversificación productiva de las explotaciones, la preocupación por el equilibrio territorial y una mayor sensibilidad hacia el medio ambiente (Menor Toribio, 2000: 416). Sin embargo, posteriormente el concepto de postproductivismo fue criticado por ser excesivamente generalista, dualista y poco teórico, así como por la escasez de evidencias empíricas que demostraran una ruptura con el productivismo (Wilson, 2001; Evans et al., 2002).

Así, algunos autores pusieron énfasis en la necesidad de desarrollar nuevos enfoques teoréticos que permitieran entender mejor los cambios en el mundo rural, de manera que poco a poco se abandonó el concepto de postproductivismo y aparecieron nuevas conceptualizaciones centradas en la multifuncionalidad de las áreas rurales (Woods, 2011: 80). La idea de multifuncionalidad deja de concebir el espacio rural únicamente como espacio de producción y, por el contrario, sostiene que el valor de la agricultura no reside solamente en los bienes que produce, sino también en los beneficios sociales y ambientales que genera, como el mantenimiento de los paisajes y las tradiciones rurales, la protección de la biodiversidad, la conservación de los suelos, la generación de ocupación, la contribución a la salud y la mejora de la seguridad alimentaria (Atance y Tió, 2000; Reig Martínez, 2002).

En consecuencia, la multifuncionalidad de la agricultura conlleva la multifuncionalidad del territorio y, como tal, ha sido considerada por varios autores como el núcleo del nuevo paradigma de desarrollo rural, ya que permite reconstituir el valor de la agricultura y de los territorios rurales, adaptándolos a las necesidades de la sociedad actual, deseosa de consumir y experimentar el campo (Knickel y Renting, 2000: 513; Marsden y Sonnino, 2008).

En cualquier caso, como esa multifuncionalidad se da en un contexto capitalista, la sociedad ha buscado la forma de explotar los beneficios sociales y ambientales de la agricultura y de la ruralidad en general para obtener ingresos económicos. Así, atributos como el paisaje, la naturaleza, el patrimonio o la cultura han sido convertidos en mercancías que se pueden comprar y vender. Como resultado, las áreas rurales han dejado de ser únicamente espacios de producción y ahora son también espacios de consumo, configurando así un escenario mucho más polivalente que en el pasado (Armesto López, 2000).

La mercantilización de lo rural se produce porque su valor de intercambio (es decir, lo que los consumidores están dispuestos a pagar para gozar del espacio rural), es superior a su valor de uso por parte de la población local, lo que se ha traducido en un auge del uso residencial (Dijst et al., 2005) y de nuevas actividades, especialmente relacionadas con el ocio y el turismo (Posada, 1999). En este sentido, actividades como la gestión del medio ambiente, la producción de energías renovables o el agroturismo, no solo constituyen una oportunidad adicional para los agricultores, sino que además se adaptan plenamente a las 
demandas actuales de la sociedad (van der Ploeg y Roep, 2003: 43). Así pues, la pluriactividad, en clave interna, y la multifuncionalidad, en clave externa, aparecen estrechamente relacionadas en el proceso de reinvención de las áreas rurales, facilitando el aumento de la renta individual o colectiva (Rubio Terrado, 2010).

Dentro del proceso de mercantilización del campo, tanto los productores como los consumidores juegan un papel clave, pues ambos contribuyen a crear nuevos significados para los objetos y a convertir las actividades rurales cotidianas en experiencias que, en una situación óptima, tienen que corresponderse con las expectativas de los consumidores (Fløysand y Jakobsen, 2007). En este punto, conviene hacer una breve referencia al modelo de destrucción creativa (Mitchell, 1998), una teoría donde se advierte que una excesiva mercantilización del patrimonio puede propiciar una pérdida de la condición de rural, lo que se traducirá en un declive del turismo, debido a la incapacidad de poder seguir ofreciendo una experiencia rural.

En todo caso, el proceso de mercantilización del patrimonio local y su aprovechamiento para generar desarrollo nos remite directamente al concepto de economía de la cultura sugerido por Ray $(1998 ; 1999 ; 2001)$, un concepto ideado para referirse a los enfoques de desarrollo rural que se basan en una revalorización del lugar a partir de la cultura. Según Ray (2001), el desarrollo rural pasa inevitablemente por un uso estratégico de la cultura, incluyendo la gastronomía, el idioma, la artesanía, el folklore local o el paisaje, pero subraya que este repertorio de desarrollo no tiene que ser necesariamente mercantilizado, sino que también puede ser objeto de promoción interna o externa, o dar lugar a la redefinición y fortalecimiento de la identidad local.

En este sentido, el aprovechamiento de la cultura local como motor de desarrollo rural ha llevado muchos territorios a centrar sus estrategias de desarrollo en la visibilidad del territorio (Lee et al., 2005: 274). Este hecho nos invita a hacer un inciso en el concepto de branding territorial o de lugares, que consiste en la vinculación de un territorio a una marca, con el objetivo de reforzar su reputación, fomentar la fidelidad, garantizar la calidad, transmitir valores y ofrecer una noción de pertinencia (de San Eugenio y Barniol, 2012: 420). De hecho, la creación de marcas territoriales es (y volvemos al principio) una de las fórmulas que ha permitido traducir la multifuncionalidad de la agricultura en desarrollo rural, a partir de la reconfiguración de los recursos locales, la redefinición del rol social de la agricultura y el incremento del valor añadido de los productos locales (Marsden y Sonnino, 2008: 425). No obstante, cabe destacar que la mayor parte de marcas territoriales creadas en áreas rurales están orientadas hacia el turismo y no hacia una economía diversificada (Lee et al., 2005: 275). En cualquier caso, las marcas territoriales permiten a las áreas rurales posicionarse y diferenciarse en un contexto cada vez más globalizado. Además, el branding territorial supone una reorientación hacia el capital local, algo que también puede conseguirse a través de los productos agroalimentarios (Horlings y Marsden, 2012). Este camino alternativo, como veremos a continuación, convierte la producción agroalimentaria en otro de los grandes bloques conceptuales que hay que tener en cuenta para entender el nuevo paradigma de desarrollo rural.

\section{III.2. La redefinición del sistema agroalimentario}

Debido al creciente reconocimiento de las áreas rurales como espacios de consumo, algunos autores han considerado que el desarrollo rural tiene que basarse en el valor de estos 
territorios para el ocio y el turismo (Böcher, 2008: 378). Sin embargo, recientemente se ha ido consolidando una nueva corriente de opinión que defiende que la agricultura está destinada a jugar un papel central en el nuevo paradigma de desarrollo rural (van der Ploeg et al., 2000: 401; Paül, 2013), ya que es la actividad que permite entrelazar el progreso socioeconómico con el medio ambiente y el paisaje cultural (Knickel y Renting, 2000: 514). En cualquier caso, para reconocer el papel central de la agricultura en el desarrollo rural, tenemos que desprendernos de las conceptualizaciones propias del modelo agroindustrial que aún separan los conceptos de producción y naturaleza (Marsden, 2006: 203). Por el contrario, hay que prestar más atención al concepto de sostenibilidad, uno de los pilares de este nuevo paradigma de desarrollo rural (Plaza Gutiérrez, 2006: 83) y que puede ser entendido como la creación de riqueza con respeto hacia el capital ecológico, humano, social y manufacturado (Marsden y Smith, 2005). Según estos mismos autores, el objetivo de un desarrollo sostenible tiene que ser afrontado desde tres criterios básicos: la retención en el ámbito local del valor de los productos, la innovación en los mecanismos de distribución de este valor y la creación de sinergias entre la agricultura y otras actividades.

La creciente adaptación de las prácticas agrarias a las demandas actuales de la sociedad, con un enfoque más local, sostenible y orientado hacia la calidad, concuerda plenamente con el nuevo paradigma de desarrollo rural (Monllor Rico, 2013) y está directamente relacionado con la transición desde el paradigma agroindustrial predominante hacia un nuevo «paradigma agroalimentario integrado y territorial» (Wiskerke, 2009: 374). En este punto, conviene centrar la atención en el denominado giro hacia la calidad que ha experimentado el sistema agroalimentario durante las últimas décadas, un fenómeno postmoderno asociado con la proliferación de redes alternativas que operan al margen de los circuitos alimentarios industriales (Goodman, 2003; Renting et al., 2003) y que se estructuran en cadenas cortas de suministro que, a su vez, están en la base de un gran número de estrategias de desarrollo rural (Marsden et al., 2000).

El emergente paradigma agroalimentario alternativo aparece como una respuesta a los problemas derivados del sistema agroindustrial y se caracteriza esencialmente por una producción vinculada al territorio, una oferta de productos frescos y de calidad, la proximidad entre productores y consumidores y la sostenibilidad ambiental (Wiskerke, 2009). Así, el giro hacia la calidad del sistema agroalimentario ha comportado también un giro local, en línea con el nuevo paradigma de desarrollo rural, pensado desde el territorio y para el territorio (Brunori, 2007).

Por lo que se refiere a las cadenas cortas de suministro, entre las cuales podemos citar a cooperativas, mercados de agricultores o puntos de venta directa, todas ellas se caracterizan por la importancia que conceden al proceso de producción y al origen del producto, así como también por la redefinición que conllevan de las relaciones entre productores y consumidores (Marsden et al., 2000). En cualquier caso, estas cadenas actúan al margen de los circuitos largos convencionales, reducen la distancia entre productores y consumidores y estrechan los vínculos entre la producción y el territorio, favoreciendo así una producción agrícola más sostenible (Renting et al., 2003: 398). Así, pues, estas redes agroalimentarias alternativas representan, en última instancia, nuevas formas de organización social que entrelazan los productores y los consumidores dentro y a través del territorio, permitiendo el arraigo de las cadenas de suministro en un espacio determinado (Marsden y Smith, 2005: 443). 
En este sentido, varios autores han destacado el papel de las cadenas cortas de suministro y, por extensión, de las redes agroalimentarias alternativas, como elementos clave en el nuevo paradigma de desarrollo rural (Marsden et al., 2000; van der Ploeg et al., 2002; Renting et al., 2003; Marsden, 2006; Gralton y Vanclay, 2009; Wiskerke, 2009). Según este último autor, las redes agroalimentarias alternativas facilitan la creación de ocupación, la generación de valor añadido, la preservación del medio rural, la reducción del transporte de los alimentos, la creación de capital social y la recuperación de la confianza en el sistema agroalimentario por parte de la sociedad (Wiskerke, 2009). Además, el establecimiento de vínculos entre los alimentos y el territorio donde han sido producidos, enfatiza la importancia de la agricultura, no solamente como actividad productiva, sino también por su papel en el mantenimiento de los espacios abiertos y la calidad del paisaje (Horlings y Marsden, 2012: 2). Así, pese a que el modelo agroindustrial continúa siendo el predominante, durante los últimos años se ha producido un aumento progresivo de iniciativas propias de este paradigma alternativo (van der Ploeg et al., 2002), como pueden ser la agricultura ecológica, la apuesta por una producción de calidad o la venta directa al consumidor, a menudo estableciendo sinergias con otros sectores económicos, especialmente el turismo (Renting et al., 2003). Asimismo, también hay que mencionar la emergencia de la agricultura social, un sector que ha convertido la agricultura en una herramienta para la reinserción de colectivos en riesgo de exclusión social, mostrándose a la vez como una estrategia válida para el desarrollo rural (Guirado et al., 2013) y para el asentamiento de nuevos pobladores, contribuyendo a mitigar la sangría demográfica de algunas zonas.

En cualquier caso, cabe destacar que la variable clave de estas redes agroalimentarias alternativas ya no es el precio, sino la calidad, un concepto construido socialmente (Goodman, 2003), pero muy relacionado con factores intangibles como la atención y el tiempo dedicado a la producción, la interacción social con el cliente, la pasión, el conocimiento, la confianza, el respeto, la creatividad o el sentido de lugar (Gralton y Vanclay, 2009: 199). Más allá del significado que se le dé, la necesidad de transmitir calidad se ha traducido en un intento de diferenciar cada producto para hacerlo único en el mercado. La calidad puede estar asociada al proceso de producción o bien al lugar de producción (Renting et al., 2003: 401), lo que convierte los distintivos de calidad y de origen en elementos relevantes para el desarrollo rural. Los distintivos de calidad, por un lado, permiten retener los beneficios dentro de la red de productores y procesadores locales, a la vez que propician la creación de nuevos organismos, estimulan el aprendizaje y fortalecen la identidad local (Tregear et al., 2007). Los distintivos de origen, por otro lado, implican dotar al producto de una identidad específica, que a su vez también fortalece la identidad territorial y la convierte en capital intelectual al alcance de los demás productores del territorio, favoreciendo así la creación de sinergias entre actividades diferentes y reafirmando el potencial de los productos agroalimentarios de calidad para generar un desarrollo rural de carácter transversal (Ray, 2001).

\section{III.3. La revitalización social}

Tal y como se ha avanzado anteriormente, el nuevo paradigma de desarrollo rural está relacionado con una serie de aspectos sociales que adquieren una gran relevancia. Esta constatación nos remite a una parte importante de la literatura, básicamente proveniente de la 
sociología, que ha puesto el énfasis en los aspectos intangibles del desarrollo rural y que se articula alrededor de un concepto tan complejo como es el capital social.

El término capital social hace referencia a las repetidas interacciones sociales entre individuos y grupos que generan confianza, derivan en normas sociales y fortalecen la cooperación y la reciprocidad (Lee et al., 2005: 270). Desde esta concepción, el capital social no pertenece a los individuos o a las comunidades en sí, sino que tiene que ser entendido como una cualidad de las relaciones sociales y depende de la cantidad y la calidad de las interacciones (Bourdieu, 1980).

Para entender la importancia del capital social en los procesos de desarrollo, es necesario abordar el concepto desde un enfoque que reconozca la importancia de las redes y del contexto institucional (Woolcock y Narayan, 2000). Sin embargo, los análisis sobre el papel que juega el capital social en el desarrollo rural han tendido a focalizarse únicamente sobre el primero de estos dos aspectos, es decir, las redes de relaciones sociales y su incidencia a la hora de fortalecer la identidad colectiva y favorecer el desarrollo (Lee et al., 2005). En todo caso, se pone de manifiesto que, como ya había apuntado Coleman (1988: S98), el capital social es productivo, ya que hace posible conseguir objetivos que, en su ausencia, serían imposibles, además de generar capital humano.

Según Shucksmith (2000), el capital social ha sido un aspecto clave en la implementación de muchos proyectos LEADER de desarrollo rural, debido al hecho de que la capacidad de acción ha sido mayoritariamente interpretada a nivel comunitario, con lo que se ha puesto mucho énfasis en la necesidad de desarrollar las capacidades colectivas y no tanto las individuales. Esta constatación nos remite a la teoría del desarrollo rural comunitario de Murray y Dunn (1995), en la que los autores defienden que el requisito esencial para lograr un desarrollo impulsado desde abajo y a largo plazo, es precisamente la construcción de capacidades, un concepto que hace referencia al incremento, por parte de la comunidad rural, de las habilidades relacionadas con el liderazgo, la mediación, la resolución de conflictos, el trabajo en grupo, la comprensión de los asuntos de gobierno o la consecución de una visión de futuro común. La construcción de capacidades es el proceso que permite dotar a los actores locales de una mayor experiencia organizativa, facilitando así que estos actores puedan gestionar sus propios asuntos con autonomía. En una línea similar, son varios los autores que han subrayado la construcción de capacidades como un factor clave para el desarrollo rural, un hecho que requiere de la existencia de redes de relaciones sociales (Wellbrock et al., 2012) y que no solamente es necesaria dentro de la sociedad civil, sino también a nivel institucional (Ward et al., 2005).

En cualquier caso, la construcción de capacidades y la consecución de un mayor grado de autonomía van estrechamente ligadas con la noción de gobernanza, un concepto que hace referencia a las nuevas formas de coordinación política descentralizada, donde las fronteras entre el sector público y privado son difusas (Stoker, 1998) y donde los actores locales adquieren un papel influyente en las decisiones políticas, trabajando codo a codo con la administración por unos objetivos compartidos (Paül, 2013). Así pues, la gobernanza es el factor que explica la creciente capacidad de los individuos y las instituciones implicadas en un proceso de desarrollo rural para actuar conjuntamente y asumir el liderazgo del proceso (Shucksmith, 2010). Consecuentemente, la gobernanza aparece siempre acompañada de la creación de asociaciones y redes de relaciones que se rigen por principios como la movi- 
lización de los actores locales, la cooperación, el empoderamiento o la autonomía local (MacKinnon, 2002), elementos todos ellos muy próximos a la noción de capital social. Las nuevas formas de gobernanza han dado lugar, según Böcher (2008), a una nueva forma de hacer política mucho más efectiva de cara a los problemas locales, a la que nos podemos referir como gobernanza territorial. Este modelo de coordinación política se caracteriza por un incremento de las responsabilidades locales, la cooperación en redes, la delimitación del territorio a partir de criterios funcionales y una gran diversidad de formas de implementación de las políticas. Así, varios autores subrayan la importancia de la gobernanza territorial en los procesos de desarrollo rural, pese a apuntar que ésta no puede ser tomada como norma, sino que siempre tiene que ser cumplimentada con las formas de gobierno convencionales (Böcher, 2008; Furmankiewicz, 2012: 265; Paül, 2013).

En todo caso, de todo ello se desprende que el desarrollo rural depende, en gran medida, de la habilidad de los actores locales para desarrollar estructuras organizativas y capacidad institucional que faciliten la aplicación de nuevas estrategias territoriales. Por este motivo, otro concepto fundamental para entender el nuevo paradigma de desarrollo rural es el de innovación social, que hace referencia a los cambios de actitudes, comportamientos y percepciones que propician nuevas formas de colaboración entre los actores de una red y que, a su vez, se traducen en algún tipo de mejora tangible (Neumeier, 2012). Algunos ejemplos de innovación social que vienen caracterizando el nuevo paradigma de desarrollo rural son, entre otros, la construcción de capacidades a nivel colectivo, la creación de redes de relaciones o la construcción de imágenes e identidades territoriales (Dargan y Shucksmith, 2008: 284).

Para terminar, conectando todos estos aspectos sociales con la esfera económica, conviene citar a Marsden y Smith (2005: 442), quienes apuntan que variables como la presencia de redes de relaciones, el conocimiento tácito, las habilidades y creatividad de los actores locales, el compromiso con la comunidad o la existencia de una visión compartida, son claves en el desarrollo rural, por el simple hecho de ser los elementos que permiten que proveedores, productores y consumidores establezcan relaciones beneficiosas mutuamente, basadas en la confianza y el compromiso.

\section{RECONCEPTUALIZANDO EL DESARROLLO RURAL}

\section{IV.1. Propuesta de consenso alrededor de un solo término conceptual}

En primer lugar, queremos remarcar la confusión que genera, ya en principio, el hecho de que exista una multitud de términos diferentes para hacer referencia al nuevo enfoque de desarrollo rural. Este factor constituye, a nuestro entender, un obstáculo para concretar el nuevo paradigma de desarrollo rural como objeto de estudio y solo puede generar confusión, ya que no siempre resulta obvio que todas las variaciones terminológicas hagan referencia al mismo concepto. En este sentido, creemos conveniente que el mundo académico llegue a un cierto consenso para utilizar un único término, una vez constatado que los autores que hablan de desarrollo rural endógeno, por citar un ejemplo, están haciendo referencia al mismo fenómeno que aquellos otros que hablan de desarrollo rural integrado, sostenible, local, regional o, incluso, neo-endógeno. 
Así, si tenemos presente que la actual concepción de desarrollo (aplicado al territorio) ya lleva intrínsecas nociones como sostenibilidad, territorialidad y transversalidad (Pike et al., 2007), nosotros apostamos por consolidar el uso del término más básico (desarrollo rural) para hacer referencia a este nuevo paradigma y por abandonar todas aquellas variantes terminológicas que no aportan ninguna variación semántica y solamente generan confusión e inconcreción. En este sentido, suscribimos plenamente las opiniones que consideran necesario dejar de pensar el desarrollo endógeno y exógeno como categorías excluyentes (High y Nemes, 2007: 5; Gralton y Vanclay, 2009: 195; Galdeano-Gómez et al., 2011; Furmankiewicz, 2012: 265), a la vez que no compartimos la necesidad de inventar nuevos conceptos como desarrollo neo-endógeno, pues no deja de significar lo mismo que un desarrollo endógeno concebido de forma flexible (Long y van der Ploeg, 1994; Bowler, 1999).

Por otro lado, consideramos preferible que el concepto de desarrollo rural no sea complementado con adjetivos geográficos como local o regional, ya que pese a no distorsionar el significado del concepto, sí pueden generar confusión, dado que su significado no es universal y la escala local en un contexto geográfico determinado puede equivaler a la escala regional en otro contexto distinto (Pike et al., 2007). En definitiva, ya que el significado del desarrollo rural cambia en el tiempo y el espacio, admitiendo múltiples interpretaciones, consideramos que nos podemos permitir el lujo de no añadir más complejidad al concepto y facilitar su concreción como objeto de estudio a través de su identificación mediante un único término simple y flexible.

\section{IV.2. La necesidad de avanzar hacia una visión de conjunto del fenómeno}

En segundo lugar, queremos poner de manifiesto que las múltiples aportaciones teóricas sobre desarrollo rural efectuadas desde principios del siglo XXI y desde una gran diversidad de disciplinas se han traducido, a nuestro entender, en una literatura en cierto modo fragmentada; eso es, que deambula entre una gran diversidad de conceptos y cuestiones teóricas que han sido profundamente estudiados por separado, pero escasamente relacionados entre sí.

Así, para empezar, hemos visto cómo algunos autores han centrado sus aportaciones teóricas en cuestiones como la multifuncionalidad de la agricultura y la diversificación económica de las áreas rurales, mientras que otros han puesto énfasis en la mercantilización del patrimonio rural, la promoción de la cultura e identidad local o la importancia de las marcas territoriales. Paralelamente, hemos identificado otro gran bloque literario centrado exclusivamente en el sector agroalimentario, pero que incluye una gran diversidad de cuestiones, desde la producción de calidad hasta las cadenas cortas de suministro o la sostenibilidad de las prácticas agrarias. Finalmente, hemos mostrado también cómo una parte importante de la literatura, especialmente proveniente de la sociología, se ha centrado en los aspectos sociales del desarrollo rural, lo que ha permitido mejorar la teoría alrededor de un gran número de conceptos, como los de capital social, la gobernanza, la construcción de capacidades o la innovación social.

Sin embargo, como se habrá observado, son pocos los autores que han enfatizado las evidentes relaciones que todos estos conceptos y cuerpos teóricos guardan entre sí. En este sentido, queremos subrayar que, para entender la esencia del desarrollo rural, resulta conve- 
niente contemplar todos estos elementos a la vez y no por separado, ya que ninguno de ellos define individualmente el nuevo paradigma de desarrollo rural, pero todos ellos son piezas de un mismo puzle, con capacidad para ser una característica importante en un determinado proceso de desarrollo rural.

Veámoslo más claramente con un ejemplo: imaginemos un territorio rural con un fuerte capital social, donde existe un alto grado de colaboración entre actores locales por medio de redes de relaciones. Como punto de partida, ésta puede ser una característica importante para el desarrollo del territorio en cuestión, pero es obvio que por sí solo no conducirá automáticamente a ello. No obstante, la existencia de un capital social fuerte y de redes basadas en la proximidad, la confianza y la reciprocidad, sí que puede resultar crucial para la creación y el funcionamiento de cadenas cortas de suministro donde se podrán vender, por ejemplo, los productos agroalimentarios locales, a la vez que éstos se verán revalorizados. Un hecho así, a su vez, puede ayudar a reforzar la identidad colectiva, además de facilitar el mantenimiento de las actividades primarias que tradicionalmente han caracterizado el paisaje local. En este sentido, no podemos olvidar que un paisaje bien valorado por la sociedad podrá actuar como factor atrayente de nuevos residentes y actividades, lo que podrá facilitar la recuperación demográfica y la diversificación económica del territorio. En definitiva, tomándolo únicamente como un ejemplo para mostrar las interrelaciones entre algunos de los cuerpos teóricos identificados, hemos visto cómo la existencia de un capital social potente puede resultar clave para la promoción y revalorización de los productos locales, el mantenimiento del paisaje agrario tradicional y la revitalización económica y demográfica de una área rural.

En síntesis, es evidente que el desarrollo rural ya no responde a ninguna fórmula mágica, sino que depende siempre de una gran multitud de factores interrelacionados (Ventura et al., 2008: 151). El problema es que estos factores han sido mayoritariamente analizados por separado, sin explorar las relaciones que mantienen y que acabamos de ejemplificar. Así, tenemos la impresión de que la abundante teoría sobre el nuevo paradigma de desarrollo rural carece de unidad y que no se ha puesto suficiente énfasis en la necesidad de integrar los diferentes cuerpos teóricos que la integran. En este contexto, tal y como apuntan Messely et al. (2013: 401), resulta crucial la aparición de nuevos marcos teóricos exhaustivos que permitan afrontar la naturaleza, las dinámicas y la heterogeneidad de los procesos de desarrollo rural contemporáneos. Uno de estos marcos teóricos es el modelo de la rural web, planteado por van der Ploeg y Marsden (2008), que de forma innovadora, aporta una visión de conjunto sobre el desarrollo rural, integrando buena parte de las múltiples cuestiones teóricas identificadas en nuestra revisión de la literatura académica. A continuación, presentamos y valoramos este marco teórico, que a nuestro entender permite dar respuesta a la problemática que acabamos de identificar.

\section{IV.3. La rural web: reseña y valoración de un marco teórico innovador}

En 2007, se puso en marcha el programa de investigación ETUDE (Enlarging Theoretical Understanding of Rural Development), que tenía por objetivo adquirir una mejor comprensión de la naturaleza de los procesos de desarrollo rural, con el fin de poder elaborar nuevas propuestas destinadas a las políticas de desarrollo rural en Europa. Durante los dos años que 
duró el proyecto, el equipo de investigadores analizó 63 casos de desarrollo rural y elaboró un nuevo marco teórico que integra varios cuerpos teóricos emergentes y que permite superar los tradicionales enfoques unidisciplinarios y sectoriales. Este marco teórico se articula alrededor de un concepto clave: la rural web, que hace referencia a la constelación de personas, recursos, actividades y procesos que se encuentran e interactúan en un territorio. A partir de aquí, los autores del modelo definen el desarrollo rural como un proceso continuo de «despliegue» o «revitalización» de la rural web local. En otras palabras, el desarrollo rural de un territorio se basa y a la vez está dirigido por su propia rural web, es decir, por el tejido de personas, recursos, actividades y procesos que se interrelacionan y modelan conjuntamente su atractivo económico, social, cultural y ambiental. La rural web de un territorio tiene que considerarse como una realidad multinivel, ya que pese a estar estructurada en el ámbito local, está relacionada con el contexto regional; como una realidad multiactor, pues incluye a individuos, instituciones, empresas, agencias y movimientos sociales; y como una realidad dinámica, dado que evoluciona con el paso del tiempo (van der Ploeg y Marsden, 2008; van der Ploeg y van Broekhuizen, 2009).

Desde un punto de vista conceptual, la rural web se estructura en 6 dimensiones teóricas que, según sus autores, son las que permiten contrarrestar la decadencia de la agricultura y a mejorar la calidad de vida en las aéreas rurales. Estas dimensiones son la endogeneidad, la producción de novedades, la sostenibilidad, el capital social, los nuevos marcos institucionales y la gobernanza de los mercados, y las interrelaciones que se establecen entre ellas son fundamentales para la fortaleza de la rural web de un territorio y, en definitiva, para su desarrollo. Así, la hipótesis central que guía este modelo es que cuando la rural web de un territorio es amplia y funciona bien, eso se traduce en una mayor competitividad de la economía local y en una mejora de la calidad de vida de su población (van der Ploeg et al., 2008: 2). La figura 1 muestra un esquema de la rural web como marco teórico, donde podemos identificar visualmente el núcleo de este modelo, las 6 dimensiones teóricas y sus interrelaciones, y sus dos grandes ámbitos de incidencia. A continuación, profundizaremos de forma más detallada en cada una de las dimensiones apuntadas.

La primera dimensión clave del desarrollo rural es la endogeneidad, que hace referencia al grado en que la economía local está basada en recursos disponibles y controlados a escala local. Así pues, la endogeneidad no tiene que ser vista como un concepto rígido que implica el uso exclusivo de recursos endógenos, sino que se refiere al equilibrio entre éstos y los exógenos, así como al grado de control que se tiene de ellos desde el ámbito local y al grado de beneficio que la riqueza producida genera sobre el propio territorio. En definitiva, la endogeneidad nos indica el grado de enraizamiento territorial de la economía local, la relevancia del espacio y la capacidad local para organizarlo. En cualquier caso, cuanto más grande sea la endogeneidad, mayor será la ventaja competitiva del territorio.

La segunda dimensión teórica de la rural web es la producción de novedades, es decir, la capacidad local para mejorar continuamente los procesos de producción, los productos y los patrones de cooperación a partir de nuevas ideas, nuevas prácticas, nuevos artefactos o nuevas combinaciones de recursos, procedimientos y conocimientos teóricos. La producción de novedades depende básicamente del conocimiento tácito, siendo así exclusiva de cada territorio y pudiendo fortalecer su dinamismo y su competitividad. 
Figura 1

ESQUEMA CONCEPTUAL DE LA RURAL WEB

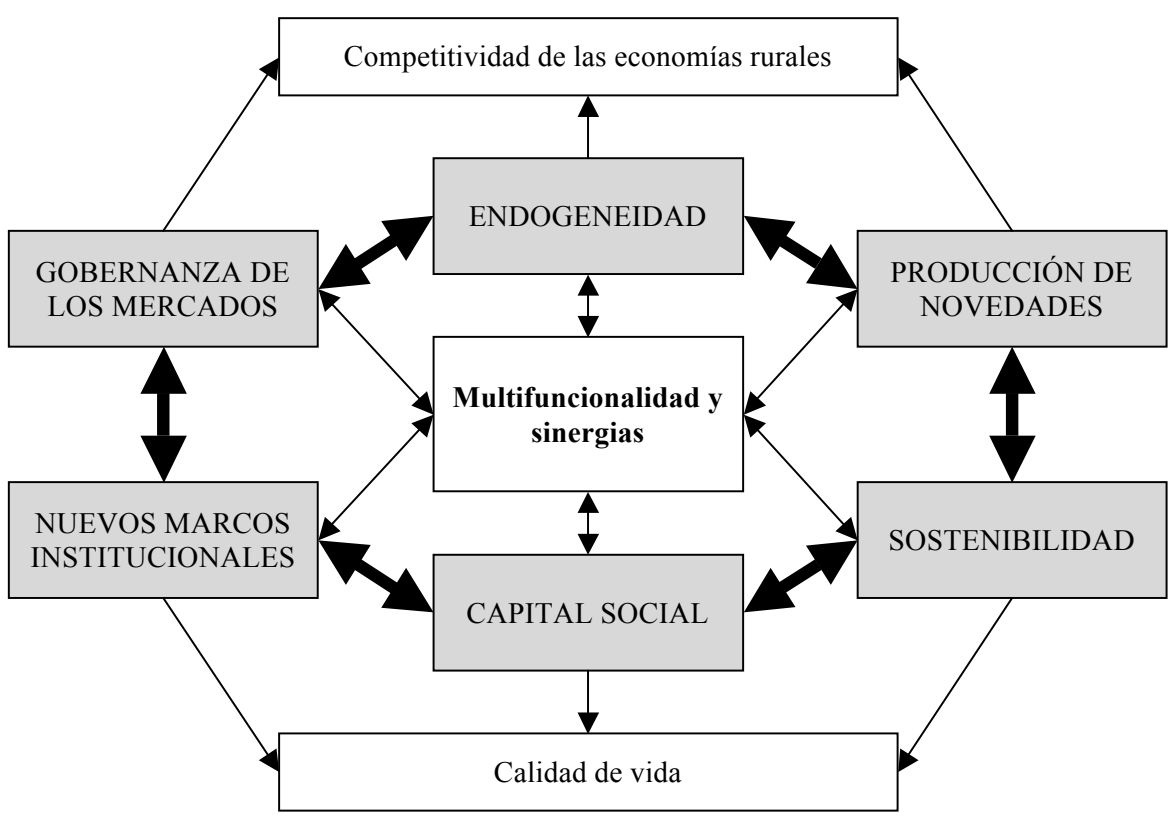

Fuente: elaboración propia a partir de Marsden y van der Ploeg (2008: ix).

La tercera dimensión a comentar es la sostenibilidad, entendida aquí como la existencia de las condiciones ecológicas y sociales necesarias para garantizar un nivel de vida aceptable para las generaciones futuras. Aplicada al desarrollo rural, la sostenibilidad tiene que ser vista como aquel elemento que permite compaginar las necesidades económicas con las sociales y las ambientales.

La cuarta dimensión identificada por van der Ploeg y Marsden en su teoría de las rural webs es la del capital social, que como hemos visto anteriormente, hace referencia al grado de colaboración entre actores para hacer cosas conjuntamente, lo cual implica a individuos, grupos, organizaciones e instituciones. El capital social depende de la capacidad de relacionarse entre una gran diversidad de actores y resulta clave para la consecución de objetivos compartidos.

La quinta dimensión clave del desarrollo rural son los nuevos marcos institucionales, es decir, la flexibilidad de las instituciones para promover la cooperación y solucionar problemas de coordinación, generando incentivos para una mayor confianza entre actores y facilitando la acción colectiva. En el desarrollo rural, la flexibilidad institucional tiene que contribuir a fomentar la participación local, favorecer la transmisión de conocimientos y proveer nuevos servicios públicos y privados.

Finalmente, la última dimensión teórica es la gobernanza de los mercados, eso es, la capacidad institucional para controlar y fortalecer los mercados existentes y crear nuevos. 
La gobernanza de los mercados está relacionada con las cadenas de suministro de bienes de consumo, el reparto del valor creado y la transferencia de beneficios generados por la acción colectiva, convirtiéndose así en un factor clave para el desarrollo rural, ya que indirectamente genera ocupación, ingresos y bienestar, refuerza la autonomía y reduce la vulnerabilidad respecto a factores externos (van der Ploeg y Marsden, 2008).

Esas seis dimensiones teóricas constituyen el conjunto de recursos disponibles en cada territorio para su propio desarrollo, ya que hacen referencia a elementos de capital ecológico, humano, social, económico y cultural. Estos cinco tipos de capital, a su vez, constituyen conjuntamente su denominado capital territorial, un concepto que hace referencia a todas las formas de capital implicadas, movilizadas y utilizadas activamente para la economía y la sociedad local. Los autores del modelo subrayan que la integración de las varias formas de capital en un conjunto más o menos coherente es un elemento crucial para el desarrollo rural (van der Ploeg et al., 2008: 13).

En definitiva, siguiendo este marco teórico, podemos hablar de desarrollo rural en un territorio cuando su rural web es revitalizada de forma que se traduce en una mejora de la calidad de vida, un hecho que tiene lugar básicamente cuando se producen contribuciones positivas gracias a un aumento de la endogeneidad, un incremento de la producción de novedades, una mejora de la sostenibilidad, un fortalecimiento del capital social, una creación de nuevos marcos institucionales y una adecuada gobernanza de los mercados más relevantes (van der Ploeg et al., 2008: 25).

El modelo teórico de la rural web ha tenido una buena aceptación dentro del mundo académico, ya que ha sido utilizado como marco teórico por varios autores, en estudios de naturaleza muy distinta (Knickel et al., 2009; Moschitz y Feldmann, 2010; Esparcia, 2014). Sin embargo, una de las grandes virtudes de este modelo es que no solamente constituye un marco teórico integrado sobre el nuevo paradigma de desarrollo rural, sino que, además, también puede ser utilizado como herramienta de diagnosis, para evaluar el potencial de desarrollo de las áreas rurales, y como herramienta analítica, para analizar y comparar diferentes procesos de desarrollo rural (Ventura et al., 2008: 168).

Precisamente, la aplicación de la rural web como herramienta analítica dentro del propio proyecto ETUDE, permitió constatar a sus autores que todo proceso de desarrollo rural se origina a partir de las interrelaciones entre dos o más de las dimensiones teóricas de la rural web que acabamos de definir. Estas dos o más dimensiones que desencadenan interrelaciones positivas entre las otras dimensiones, actúan, pues, como iniciador. A su vez, el resto de dimensiones pueden actuar, según cada caso, como resultado (cuando aparecen como producto de las interrelaciones entre otras dimensiones) o como lubricante (cuando propician una mejora de las interrelaciones entre otras dimensiones). En este sentido, los autores descubrieron que el capital social tiene un gran potencial para actuar como iniciador y como lubricante en los procesos de desarrollo rural. Asimismo, también desvelaron que la endogeneidad, la sostenibilidad y la gobernanza de los mercados tienden a aparecer como resultado de las interacciones entre otras dimensiones. Finalmente, los autores identificaron que las rural webs que tienden a ser más competitivas son aquellas que presentan un mayor grado de endogeneidad, un elevado nivel de capital social y que cuentan con nuevos marcos institucionales (Kanemasu et al., 2008; van der Ploeg y van Broekhuizen, 2009; Milone y Ventura, 2010). 
Por otro lado, la aplicación de la rural web como herramienta de análisis en el marco del proyecto ETUDE también permitió identificar cuáles son los principales tipos de estrategias de desarrollo rural que han tenido lugar en Europa desde el cambio de paradigma apuntado. Así, en primer lugar, tenemos las estrategias de innovación de los nichos de mercado, una categoría que engloba todas aquellas estrategias generadas a partir de interrelaciones entre la producción de novedades y la sostenibilidad. Estas estrategias están mayoritariamente orientadas al sector agroalimentario y hacen referencia a nuevas combinaciones de productos y mercados, en los que los distintivos de origen y de calidad adquieren un gran protagonismo.

En segundo lugar, están las estrategias basadas en las denominadas nuevas interfaces, que son aquellas que surgen de nuevos marcos institucionales que facilitan el contacto entre actores públicos y privados, entre productores y consumidores o entre diferentes sectores y actividades. Esta categoría incluye estrategias como el acortamiento de las cadenas de suministro o la oferta de nuevos bienes y servicios basados en el territorio.

Finalmente, en tercer lugar, los autores identifican las estrategias de reorientación en el capital territorial, una categoría que incluye todas aquellas estrategias originadas a partir de las interacciones entre la endogeneidad, la sostenibilidad y la gobernanza de los mercados, entre las que podemos citar la producción de alimentos específicos o vinculados a la identidad cultural, así como las estrategias de branding territorial (Horlings y Marsden, 2012).

Pese al carácter innovador del enfoque de la rural web, que ofrece un marco teórico integrado sobre el desarrollo rural, a la vez que constituye una herramienta multifuncional, el modelo también ha sido objeto de algunas críticas que hay que mencionar. Así, por un lado, algunos autores han alertado de que las definiciones de cada una de las 6 dimensiones teóricas que conforman la rural web no son suficientemente claras, con lo cual a veces es difícil establecer los límites entre ellas (Moschitz y Feldmann, 2010). Por otro lado, también se ha criticado el modelo por ser excesivamente teórico, un hecho que dificulta su uso más allá del mundo académico. En este sentido, Messely et al. (2013) subrayan la necesidad de hacer más operativa la rural web y traducirla a un lenguaje más simple, destacando que el verdadero valor del modelo subyace en su potencial para ser utilizado como método de reflexión alrededor del desarrollo rural.

\section{IV.4. Propuesta de una definición de desarrollo rural}

Durante la revisión bibliográfica efectuada, hemos abordado y relacionado un gran número de conceptos y cuestiones distintas relacionadas con el denominado nиеvo paradigma de desarrollo rural. Sin embargo, resulta sorprendente que la mayor parte de la literatura revisada está más centrada en los distintos conceptos y cuestiones teóricas que integran este nuevo paradigma, que no en el significado del desarrollo rural como objetivo.

En consecuencia, tenemos una abundante literatura que se centra en múltiples variables relevantes para conseguir algo que raramente es definido con antelación. Así pues, para completar nuestra mirada crítica sobre la bibliografía revisada, nos disponemos a construir, paso a paso, una definición propia del desarrollo rural como objetivo, que al fin y al cabo es lo que justifica que exista un nuevo paradigma de desarrollo rural. Evidentemente la definición que proponemos no es la única posible, pero consideramos que puede ayudar a entender 
mejor qué significa el desarrollo rural en el actual contexto espaciotemporal y, en definitiva, el porqué del nuevo paradigma que hemos estado analizando a partir de la bibliografía.

En primer lugar, hay que tener presente que el desarrollo rural surge como reacción a una situación adversa como es el declive de la agricultura y las economías rurales y su objetivo fundamental es revertir esta realidad (Marsden y Smith, 2005). En consecuencia, el desarrollo se trata esencialmente de un proceso de mejora, como ya lleva intrínseco el propio concepto de desarrollo. Ya no se trata pues de crecer, sino más bien de experimentar beneficios cuantitativos y cualitativos, es decir, de mejorar. En segundo lugar, el concepto de desarrollo, a diferencia del crecimiento, no está vinculado únicamente a la esfera económica, sino que es mucho más transversal, de modo que las mejoras citadas también tienen que manifestarse en el terreno social y cultural para poder hablar de desarrollo, pues ambos aspectos son claves para la calidad de vida de las personas (Ojeda Rivera, 2004: 276).

En tercer lugar, cabe recordar que la actual concepción de desarrollo lleva intrínseca la noción de sostenibilidad (Plaza Gutiérrez, 2006), lo que implica que las mejoras de las condiciones económicas, sociales y culturales no pueden ir en detrimento del medio ambiente, sino que tienen que ser respetuosas con el entorno físico. Solamente así se puede conseguir un proceso de mejora a largo plazo, que no comporte la pérdida de las particularidades locales y no genere impactos negativos sobre la salud física y emocional de las personas.

Por otro lado, hay que tener presente que el desarrollo rural es un fenómeno territorial, pero sin embargo, tiene como últimos destinatarios a las personas y, más concretamente, la calidad de vida de los residentes de las áreas rurales. La calidad de vida es el nivel de bienestar de una sociedad mesurado individualmente y depende básicamente de la salud, el acceso al conocimiento y el acceso a los recursos necesarios para llevar una vida digna (Castree et al., 2013). Así pues, el concepto de calidad de vida reafirma que no sólo las condiciones económicas son importantes para el desarrollo, sino también lo son las sociales, las culturales y las ambientales.

Finalmente, teniendo en cuenta el papel de las áreas rurales en la sociedad contemporánea, consideramos que el desarrollo rural no puede ir únicamente a favor de la población local, sino que también tiene que alinearse con las demandas de la sociedad en general (van der Ploeg y Marsden, 2008). En este sentido, los territorios rurales tienen que encontrar su significado en el contexto regional y fortalecer las relaciones con las ciudades, siempre y cuando esto no repercute negativamente sobre el entorno físico ni suponga la pérdida de sus características rurales.

Resumiendo en una sola frase los distintos apuntes realizados, la definición que proponemos para el concepto de desarrollo rural es la siguiente. A nuestro entender, el desarrollo rural puede ser entendido como la mejora de las condiciones económicas, sociales y culturales de un territorio rural, con respeto por el entorno físico y de tal forma que repercute positivamente sobre la calidad de vida de la población residente e integre el territorio en el conjunto de la sociedad.

A partir de definiciones como ésta, es cuando podemos entender mejor por qué el actual paradigma de desarrollo rural está compuesto por unos conceptos y cuestiones teóricas determinadas, y no otras. En este sentido, queremos subrayar la necesidad de que, desde el ámbito académico, no solamente se focalice en los elementos conceptuales del paradigma, sino también en su finalidad, es decir, en el desarrollo rural como objetivo. 


\section{CONCLUSIONES}

La teorización del nuevo paradigma de desarrollo rural ha avanzado mucho durante los últimos años, como así lo demuestra la gran cantidad de aportaciones teóricas que se han hecho a su alrededor. En el presente artículo, hemos realizado una revisión sintetizada de los múltiples cuerpos teóricos involucrados en su conceptualización, lo que nos ha permitido identificar tres grandes bloques temáticos que nos pueden ayudar a comprender la multidimensionalidad del desarrollo rural: un primer bloque referente a las áreas rurales como espacios de consumo, un segundo bloque centrado en los sistemas agroalimentarios y el tercero focalizado en la revitalización de la esfera social. Los resultados de este ejercicio bibliográfico pretenden poner de manifiesto que el estudio del desarrollo rural no puede limitarse al análisis de unos conceptos determinados, porque todo proceso de desarrollo rural tiene incontables implicaciones de carácter económico, social, ambiental, cultural, político, etc. que están profundamente relacionadas entre sí y que conjuntamente condicionan el éxito o el fracaso de dicho proceso.

A continuación de este ejercicio bibliográfico, ya con un espíritu más crítico, hemos sugerido que conviene reducir la diversidad de términos existentes para hacer referencia al actual enfoque de desarrollo rural y apostar por un único concepto que evite confusiones y facilite su concreción como objeto de estudio. El simple y flexible concepto de desarrollo rural cumpliría, a nuestro entender, estos requisitos, ya que aunque pueda parecer un término demasiado general, no deja de ser una construcción social, y en vista de la concepción predominante actual, podemos decir que ya lleva intrínsecos muchos de los adjetivos con los que es acompañado normalmente, como local/regional, sostenible, integrado, etc.

Posteriormente, hemos argumentado que los numerosos cuerpos teóricos que definen el nuevo paradigma de desarrollo rural han estado escasamente relacionados entre sí, con lo cual es difícil obtener una visión de conjunto sobre qué es y qué implica realmente el desarrollo rural bajo el actual paradigma. De resultas, hemos subrayado la necesidad de disponer de nuevos marcos teóricos integrados como el modelo de la rural web elaborado por van der Ploeg y Marsden (2008). Este modelo concibe el desarrollo rural como la continua revitalización del tejido de personas, actividades, recursos y procesos que se interrelacionan en un territorio determinado, modelando su atractivo económico, social, cultural y ambiental. A la vez, el modelo identifica seis dimensiones teóricas dentro del desarrollo rural, cuyas interrelaciones son claves para la competitividad de la economía y la mejora de la calidad de vida de la población local.

A nuestro entender, el modelo de la rural web podría constituir una herramienta de gran valor para concienciar a los estudiosos del desarrollo rural que este objeto de estudio no puede ser enfocado desde una única disciplina, es decir, prestando atención solamente a los aspectos económicos, o solamente a los sociales o a los ambientales. La rural web, concebida siempre como un modelo flexible, permite pensar el desarrollo rural como un fenómeno multidisciplinar que depende de una gran cantidad de factores de naturaleza distinta y en el que no existen fórmulas mágicas. Asimismo, teniendo en cuenta su aptitud para ser aplicada como herramienta de diagnosis y análisis, creemos que la rural web puede constituir un valioso instrumento para planificar políticas de desarrollo rural, a la vez que también puede ser útil para valorar y comparar procesos de desarrollo rural ya implemen- 
tados, con el fin de extraer de ellos lecciones para el futuro, que nos permitan avanzar hacia la consecución de unas áreas rurales más vivas, dinámicas, viables y atractivas.

Por último, en el presente artículo hemos alertado de la escasez de definiciones que nos ayudan a comprender qué es el desarrollo rural. En este sentido, consideramos que para entender mejor el nuevo paradigma de desarrollo rural (tan ampliamente abordado por la comunidad científica), es imprescindible elaborar definiciones sobre el desarrollo rural (entendido como objetivo o estrategia), que es lo que al fin y al cabo justifica que se haya construido un cuerpo bibliográfico tan extenso hasta el día de hoy.

\section{BIBLIOGRAFÍA}

ARMESTO LÓPEZ, X.A. (2005): «Notas teóricas en torno al concepto de postproductivismo agrario». Investigaciones Geográficas, n³6, 137-156.

ATANCE, I. y TIÓ, C. (2000): «La multifuncionalidad de la agricultura: Aspectos económicos e implicaciones sobre la política agraria». Estudios Agrosociales y Pesqueros, $\mathrm{n}^{\circ} 189$, 29-48.

BARKE, M. y NEWTON, M. (1997): «The EU LEADER Initiative and Endogenous Rural Development: the Application of the Programme in Two Rural Areas of Andalusia, Southern Spain». Journal of Rural Studies, n¹3(3), 319-341.

BÖCHER, M. (2008): «Regional Governance and Rural Development in Germany: the Implementation of LEADER+». Sociologia Ruralis, n48 (4), 372-388.

BOURDIEU, P. (1980): «Le capital social. Notes provisoires». Actes de la recherche en sciences sociales, $\mathrm{n}^{\circ} 31$ (2), 2-3.

BOWLER, I. (1999): «Endogenous agricultural development in Western Europe». Tijdschrift voor Economische en Sociale Geografie, nº9 (3), 260-271.

BRUNORI, G. (2007): «Local food and alternative food networks: a communication perspective». Anthropology of Food, ${ }^{\circ}{ }^{\circ}$ 2 2. http://aof .revues.org/430.

CAPPELLIN, R. (1992): «Theories of Local Endogenous Development and International Cooperation» en Development Issues and Strategies in the New Europe: Local, Regional and Interregional Perspectives (Tykkyläinen, M., ed.). Aldershot, Avebury, 1-19.

CASTREE, N., KITCHIN, R. y ROGERS, A. (2013): A Dictionary of Human Geography. Oxford, Oxford University Press.

CEBRIÁN ABELLÁN, A. (2003): «Génesis, método y territorio del desarrollo rural con enfoque local». Papeles de Geografía, n³8, 61-76.

COLEMAN, J.S. (1988): «Social Capital in the Creation of Human Capital». The American Journal of Sociology, ${ }^{\circ} 94$ (suplemento), S95-S120.

DALLA ROSA, G. (1999): «Algunas reflexiones sobre la metodología del Desarrollo Local a partir del ejemplo francés» en Manual de Desarrollo Local (Rodríguez Gutiérrez, F., coord.). Gijón, Ediciones Trea, 33-41.

DARGAN, L. y SHUCKSMITH, M. (2008): «LEADER and Innovation». Sociologia Ruralis, n'48 (3), 274-291.

DE SAN EUGENIO, J. y BARNIOL, M. (2012): «Marcas territoriales y desarrollo local en la Cataluña interior. Estudio de caso: Territoris serens (el Lluçanès)». Documents d'Anàlisi Geogràfica, nº58 (3), 417-439. 
DIJST, M., ELBERSEN, B. y WILLIS, K. (2005): «The Challenge of Multi-functional Land Use in Rural Areas». Journal of Environmental Planning and Management, $\mathrm{n}^{\circ} 48$ (1), 3-6.

ESPARCIA, J. (2014): «Innovation and networks in rural areas. An analysis from European innovative projects». Journal of Rural Studies, n³4, 1-14.

EVANS, N., MORRIS, C. y WINTER, M. (2002): «Conceptualizing agriculture: a critique of post-productivism as the new orthodoxy». Progress in Human Geography, n²6 (3), 313-332.

FLØYSAND, A. y JAKOBSEN, S.-E. (2007): «Commodification of rural places: A narrative of social fields, rural development, and football». Journal of Rural Studies, n²3 (2), 206-221.

FURMANKIEWICZ, M. (2012): «LEADER+ Territorial Governance in Poland: Successes and Failures as a Rational Choice Effect». Tijdschrift voor Economische en Sociale Geografie, $\mathrm{n}^{\circ} 103$ (3), 261-275.

FURTADO, C. (1961): Desenvolvimento e subdesenvolvimento. Rio de Janeiro. Fundo de Cultura.

GALDEANO-GÓMEZ, E., AZNAR-SÁNCHEZ J.A. y PÉREZ-MESA, J.C. (2011): «The Complexity of Theories on Rural Development in Europe: An Analysis of the Paradigmatic Case of Almería (South-east Spain)». Sociologia Ruralis, no51 (1), 54-78.

GARCÍA RAMON, M.D., TULLA Y PUJOL, A.F. y VALDOVINOS PERDICES, N. (1995): Geografía rural. Madrid. Síntesis.

GOODMAN, D. (2003): «The quality 'turn' and alternative food practices: reflections and agenda». Journal of Rural Studies, ${ }^{\circ} 19$ (1), 1-7.

GRALTON, A. y VANCLAY, F. (2009): «Artisanality and culture in innovative regional agri-food development: lessons from the Tasmanian artisanal food industry». International Journal of Foresight and Innovation Policy, n 5 5 (1-3), 193-204.

GREEN, B. (1981): Countryside conservation. The protection and management of amenity ecosystems. Londres. Unwin Hyman, 1989.

GUINJOAN, E., BADIA, A. y TULLA, A.F. (2014): «El nou mosaic agroforestal del Priorat (Tarragona). Una anàlisi quantitativa dels canvis d'usos i cobertes del sòl durant el període de desenvolupament local». Documents d'Anàlisi Geogràfica, no 60 (1), 87-113.

GUIRADO, C., BADIA, A., TULLA, A.F., VERA, A. y VALLDEPERAS, N. (2013): «L'agricultura social. Aproximació conceptual i dinàmica en el context europeu». Biblio 3W. Revista Bibliográfica de Geografía y Ciencias Sociales, vol. XVIII, nº1046.

HERNANDO, M. (2007): El desenvolupament local. Barcelona. Editorial UOC.

HIGH, C. y NEMES, G. (2007): «Social learning in LEADER: Exogenous, endogenous and hybrid evaluation in rural development». Sociologia Ruralis, nº47 (2), 103-119.

HOGGART, K. y PANIAGUA, A. (2001): «What rural restructuring?» Journal of Rural Studies, ${ }^{\circ} 17$ (1), 41-62.

HORLINGS, L.G. y MARSDEN, T. (2012): «Exploring the «New Rural Paradigm» in Europe: Eco-economic strategies as a counterforce to the global competitiveness agenda». European Urban and Regional Studies, n²1 (1), 4-20.

KANEMASU, Y., SONNINO, R., MARSDEN, T. y SCHNEIDER, S. (2008): «Testing the Web: A Comparative Analysis» en Unfolding Webs: the Dynamics of Regional Rural Development (van der Ploeg, J.D. y Marsden, T., eds.). Assen, Royal Van Gorcum, 175-210. 
KITCHEN, L. y MARSDEN, T. (2009): «Creating Sustainable Rural Development through Stimulating the Eco-economy: Beyond the Eco-economic Paradox?» Sociologia Ruralis, n49 (3), 273-294.

KNICKEL, K., BRUNORI, G., RAND, S. y PROOST, J. (2009): «Towards a better conceptual framework for innovation processes in agriculture and rural development: from linear models to systemic approaches» en 8th European IFSA Symposium: Empowerment of the rural actors: A renewal of Farming Systems perspectives. Clermont-Ferrand (Francia), 6-10 de julio de 2008.

KNICKEL, K. y RENTING, H. (2000): «Methodological and Conceptual Issues in the Study of Multifunctionality and Rural Development». Sociologia Ruralis, nº40 (4), 512-528.

LEE, J., ÁRNASON, A., NIGHTINGALE, A. y SHUCKSMITH, M. (2005): «Networking: Social Capital and Identities in European Rural Development». Sociologia Ruralis, $\mathrm{n}^{\circ} 45$ (4), 269-283.

LONG, A. y VAN DER PLOEG, J.D. (1994): «Endogenous Development: Practices and Perspectives» en Born from within: Practice and Perspectives of Endogenous Rural Development (van der Ploeg, J.D. y Long, A., eds.). Assen, van Gorcum, 1-6.

LOWE, P., MURDOCH, J. y WARD, N. (1995): «Networks in rural development: Beyond exogenous and endogenous models» en Beyond Modernization: The Impact of Endogenous Rural Development (van der Ploeg, J.D. y van Dijk, G., eds.). Assen, van Gorcum, 87-106.

MACKINNON, D. (2002): «Rural governance and local involvement: assessing state-community relations in the Scottish Highlands». Journal of Rural Studies, nº18 (3), 307-324.

MARKANTONI, M., KOSTER, S., STRIJKER, D. y WOOLVIN, M. (2013): «Contributing to a Vibrant Countryside? The Impact of Side Activities on Rural Development». Tijdschrift voor Economische en Sociale Geografie, $\mathrm{n}^{\circ} 104$ (3), 292-307.

MARSDEN, T. (2006): «The road towards sustainable rural development: issues of theory, policy and practice in a European context» en Handbook of Rural Studies (Cloke, P., Marsden, T. y Mooney, P.H., eds.). Londres, SAGE Publications, 201-212.

MARSDEN, T., BANKS, J. y BRISTOW, G. (2000): «Food Supply Chain Approaches: Exploring their Role in Rural Development». Sociologia Ruralis, n40 (4), 424-438.

MARSDEN, T. y SMITH, E. (2005): «Ecological entrepreneurship: sustainable development in local communities through quality food production and local branding». Geoforum, $\mathrm{n}^{\mathrm{o}} 36(4), 440-451$.

MARSDEN, T. y SONNINO, R. (2008): «Rural development and the regional state: Denying multifunctional agriculture in the UK». Journal of Rural Studies, n ${ }^{\circ} 24$ (4), 422-431.

MARSDEN, T. y VAN DER PLOEG, J.D. (2008): «Preface: Exploring the Rural Web» en Unfolding Webs: the Dynamics of Regional Rural Development (van der Ploeg, J.D. y Marsden, T., eds.). Assen, Royal Van Gorcum, vii-ix.

MENOR TORIBIO, J. (2000): «Reflexiones en torno a los modelos productivista y postproductivista en la Vega de Granada». Cuadernos Geográficos, n³0, 415-427.

MESSELY, L., ROGGE, E. y DESSEIN, J. (2013): «Using the rural web in dialogue with regional stakeholders». Journal of Rural Studies, n³2, 400-410.

MILONE, P. y VENTURA, F. (2010): Networking the rural: the future of green regions in Europe. Assen. Royal Van Gorcum. 
MITCHELL, C.J.A. (1998): «Entrepreneurialism, commodification and creative destruction: a model of post-modern community development». Journal of Rural Studies, $\mathrm{n}^{\mathrm{o}} 14$ (3), 273-286.

MONLLOR RICO, N. (2013): «La nova pagesia: vers un nou model agrosocial». Quaderns Agraris, $\mathrm{n}^{\circ} 35,7-24$.

MOSCHITZ, H. y FELDMANN, C. (2010): «Communication in the rural web: a case study of the dairy in Andeer» en 9th European IFSA Symposium: Building sustainable rural futures: The added value of systems approaches in times of change and uncertainty. Viena (Austria), 4-7 de julio de 2010.

MURRAY, M. y DUNN, L. (1995): «Capacity Building for Rural Development in the United States». Journal of Rural Studies, $\mathrm{n}^{\circ} 11$ (1), 89-97.

NEUMEIER, S. (2012): «Why do Social Innovations in Rural Development Matter and Should They be Considered More Seriously in Rural Development Research? - Proposal for a Stronger Focus on Social Innovations in Rural Development Research». Sociologia Ruralis, n52 (1), 48-69.

OJEDA RIVERA, J.F. (2004): «El paisaje -como patrimonio- factor de desarrollo de las áreas de montaña». Boletín de la Asociación de Geógrafos Españoles, n³8, 273-278.

OLIVA SERRANO, J. (1997): «Estructuración y reestructuración de espacios y sociedades rurales: nuevas reflexiones sobre unos procesos no esperados». Zainak, n 14, 321-337.

PAÜL, V. (2013): «Hopes for the countryside's future. An analysis of two endogenous development experiences in south-eastern Galicia». Journal of Urban and Regional Analysis, $\mathrm{n}^{\circ} \mathrm{V}(2), 169-192$.

PIKE, A., RODRÍGUEZ-POSE, A. y TOMANEY, J. (2007): «What Kind of Local and Regional Development and for Whom?» Regional Studies, nº41 (9), 1253-1269.

PLAZA GUTIÉRREZ, J.I. (2006): «Territorio, geografía rural y políticas públicas. Desarrollo y sustentabilidad en las áreas rurales». Boletín de la Asociación de Geógrafos Españoles, $\mathrm{n}^{\circ} 41,39-65$.

POSADA, M. (1999): «El espacio rural entre la producción y el consumo: algunas referencias para el caso argentino». EURE, v.25, nº75, 63-76.

PUJADAS, R. (2003): «Ordenació del territori y desenvolupament local: l'exemple de la zona del Montsec» en Patrimoni, turisme y desenvolupament local (Paunero, X., ed.). Girona. Universitat de Girona.

RAY, C. (1998): «Culture, Intellectual Property and Territorial Rural Development». Sociologia Ruralis, n³8 (1), 3-20.

RAY, C. (1999): «Towards a Meta-Framework of Endogenous Development: Repertoires, Paths, Democracy and Rights». Sociologia Ruralis, n³9 (4), 521-537.

RAY, C. (2001): Culture economies: a perspective on local rural development in Europe. Centre for Rural Economy, Dept. of Agricultural Economics and Food Marketing, University of Newcastle upon Tyne. http://www.ncl.ac/cre/publish/Books/CultureEconfinal.pdf.

REIG MARTÍNEZ, E. (2002): «La multifuncionalidad del mundo rural». Información Comercial Española, ICE: Revista de Economía, no803, 33-44.

RENTING, H., MARSDEN, T. y BANKS, J. (2003): «Understanding alternative food networks: exploring the role of short food supply chains in rural development». Environment and Planning A, n³5 (3), 393-411. 
RUBIO TERRADO, P. (2010): «Modelización de los cambios y evolución reciente del sistema rural español». Boletín de la Asociación de Geógrafos Españoles, n 54, 203-235.

SHUCKSMITH, M. (2000): «Endogenous Development, Social Capital and Social Inclusion: Perspectives from LEADER in the UK». Sociologia Ruralis, nº40 (2), 208-218.

SHUCKSMITH, M. (2010): «Disintegrated Rural Development? Neo-endogenous Rural Development, Planning and Place-Shaping in Diffused Power Contexts». Sociologia Ruralis, n'50 (1), 1-14.

STÖHR, W.B. (1992): «Local initiative networks as an instrument for the development of peripheral areas» en Development Issues and Strategies in the New Europe: Local, Regional and Interregional Perspectives (Tykkyläinen, M., ed.). Aldershot, Avebury, 203-209.

STOKER, G. (1998): «Public-private partnerships and urban governance» en Partnerships in Urban Governance: European and American Experience (Pierre, J., ed.). Londres, Macmillan, 34-51.

TAYLOR, P.J. (1989): «The error of developmentalism in human geography» en Horizons in Human Geography (Gregory, D. y Walford, R., eds.). Londres, Macmillan, 303-319.

TERLUIN, I.J. (2003): «Differences in economic development in rural regions of advanced countries: an overview and critical analysis of theories». Journal of Rural Studies, $\mathrm{n}^{\circ} 19$ (3), 327-344.

TREGEAR, A., ARFINI, F., BELLETTI, G. y MARESCOTTI, A. (2007): «Regional foods and rural development: The role of product qualification». Journal of Rural Studies, $\mathrm{n}^{\circ} 23$ (1), 12-22.

VAN DER PLOEG, J.D., LONG, A. y BANKS, J. (2002): Living countrysides: Rural development processes in Europe. The state of the art. Doetinchem. Elsevier.

VAN DER PLOEG, J.D. y MARSDEN, T. (2008): Unfolding Webs: the Dynamics of Regional Rural Development. Assen. Royal Van Gorcum.

VAN DER PLOEG, J.D., RENTING, H., BRUNORI, G., KNICKEL, K., MANNION, J., MARSDEN, T., DE ROEST, K., SEVILLA-GUZMÁN, E. y VENTURA, F. (2000): «Rural Development: From Practices and Policies towards Theory». Sociologia Ruralis, n40 (4), 391-408.

VAN DER PLOEG, J.D. y ROEP, D. (2003): «Multifunctionality and rural development: the actual situation in Europe» en Multifunctional agriculture: a new paradigm for European agriculture and rural development (van Huylenbroeck, G. y Durand, G., eds.). Aldershot, Ashgate, 37-53.

VAN DER PLOEG, J.D. y VAN BROEKHUIZEN, R. (2009): «ETUDE Final Activity Report». Enlarging the theoretical understanding of rural development (ETUDE). Wageningen. ETUDE Consortium.

VAN DER PLOEG, J.D., VAN BROEKHUIZEN, R., BRUNORI, G., SONNINO, R., KNICKEL, K., TISENKOPFS, T. y OOSTINDIE, H. (2008): «Towards a Framework for Understanding Regional Rural Development» en Unfolding Webs: the Dynamics of Regional Rural Development (van der Ploeg, J.D. y Marsden, T., eds.). Assen, Royal Van Gorcum, 1-28.

VANCLAY, F. (2011): «Endogenous rural development from a sociological perspective» en Endogenous Regional Development: Perspectives, measurement and empirical investigation (Stimson, R., Stough, R.R. y Nijkamp, P., eds.). Cheltenham y Northampton, Edward Elgar, 59-72. 
VÁZQUEZ BARQUERO, A. (2007): «Desarrollo endógeno. Teorías y políticas de desarrollo territorial». Investigaciones Regionales, $\mathrm{n}^{\circ} 11,183-210$.

VENTURA, F., BRUNORI, G., MILONE, P. y BERTI, G. (2008): «The Rural Web: A Synthesis» en Unfolding Webs: the Dynamics of Regional Rural Development (van der Ploeg, J.D. y Marsden, T., eds.). Assen, Royal Van Gorcum, 149-174.

WARD, N., ATTERTON, J., KIM, T.-Y., LOWE, P., PHILLIPSON, J. y THOMPSON, N. (2005): «Universities, the Knowledge Economy and 'Neo-Endogenous Rural Development'». Centre for Rural Economy Discussion Paper Series, $\mathrm{n}^{\circ} 1,1-15$.

WELLBROCK, W., ROEP, D. y WISKERKE, J. (2012): «An integrated perspective on rural regional learning». European Countryside, nº4 (1), 1-16.

WILSON, G.A. (2001): «From productivism to post-productivism... and back again? Exploring the (un)changed natural and mental landscapes of European agriculture». Transactions of the Institute of British Geographers, $\mathrm{n}^{\circ} 26$ (1), 77-102.

WISKERKE, J.S.C. (2009): «On Places Lost and Places Regained: Reflections on the Alternative Food Geography and Sustainable Regional Development». International Planning Studies, $\mathrm{n}^{\circ} 14$ (4), 369-387.

WOODS, M. (2011): Rural. Oxon y Nueva York. Routledge.

WOOLCOCK, M. y NARAYAN, D. (2000): «Social Capital: Implications for Development Theory, Research, and Policy». The World Bank Research Observer, n ${ }^{\circ} 15$ (2), 225-249. 